\title{
PERCURSOS DE UMA DESMONTAGEM Memórias autobiográficas num processo artístico-metodológico ${ }^{1}$ \\ PATHWAYS OF A REMOVAL Autobiographical memories in an artistic and methodological process
}

Sigrid Bitter ${ }^{2}$

\section{RESUMO}

A proposta deste artigo é apresentar a arte atravessando a minha história de vida e as minhas escolhas pessoais, por meio de um processo de desmontagem apresentado na disciplina Pedagogia(s) do Teatro: Práticas Contemporâneas, ministrada pelos professores: Dra. Mara Leal e Dra. Ileana Diéguez, do programa DINTER UNIRIO/UFU-2013. Este texto aponta também para um possível conceito de desmontagem e como ela vem sendo apresentada, além de observações e socializações oriundas das desmontagens dos colegas e a narrativa de minha própria desmontagem: memórias autobiográficas num processo artístico-metodológico. Ao final, trago uma reflexão sobre todo o processo.

Palavras-chave: Desmontagem, Autobiografia, Práticas Pedagógicas.

\section{RESUMEN}

El propósito de este artículo es presentar el arte a través de mi historia de vida familiar y mis elecciones personales, a través de un proceso de desmontaje que se ha mostrado en la disciplina Pedagogía (s) del Teatro: Prácticas Contemporáneas, enseñan maestros: Dr. Mara Leal e Dr. Ileana Diéguez del programa DINTER UNIRIO/UFU-2013. Este texto también apunta a un posible concepto de desmontaje y a la forma en que se ha presentado, así como observaciones y socializaciones surgidas de la desmontaje de mis colegas y la narración de mi propia desmontaje: recuerdos autobiográficos de un proceso artístico-metodológico. Al final, yo traigo una reflexión sobre todo el proceso.

Palabras clave: Desmontaje, Autobiografía, Prácticas pedagógicas.

\section{ABSTRACT}

The purpose of this paper is to present art through my story of family life and my personal choices through a process of disassembly shown in the discipline Pedagogy (s) of the Theatre: Contemporary Practices, taught by professors: Dr. Mara Leal e Dr. Ileana Diéguez, of DINTER UNIRIO/UFU-2013 program. This text also points to a possible concept of disassembly and how it has been presented, as well as observations and socializations arising from my colleagues' disassemblies and the narrative of my own disassembly: autobiographical memories of an artisticmethodological process. At the end, I bring a reflection about the whole process.

Keywords: Disassembly, Autobiography, Pedagogical Practices.

\footnotetext{
${ }^{1}$ Uma versão reduzida do texto foi publicada nos Anais da ABRACE (Associação Brasileira de Pesquisa e Pós Graduação em Artes Cênicas) em 2013. A reduced version of the text was published in the Annals of ABRACE (Brazilian Association for Research and Pos Graduate in Theatre) in 2013.

${ }^{2}$ Professora do curso de Educação Física da UFU, doutoranda em Artes Cênicas no DINTER UFU/UNIRIO-2013. Pesquisa em andamento na área da dança com orientação da Dra. Nara Keiserman.
} 


\section{Introdução:}

Existem controvérsias quanto ao significado das palavras "desconstrução" e “desmontagem”. Ambas, assim como “desvelar", “destecer” e outras, são ou podem ser utilizadas para falar da ação do autor/artista de expor ao público o caminho pelo qual a sua obra percorreu.

Para Jaques Derrida (1997), a palavra “desconstrução" pode ter significados diferentes conforme o contexto. No idioma latino, desconstruir envolve desmembramento das partes de um todo. Desconstruir também foi um gesto estruturalista, em qualquer caso, como também um gesto antiestruturalista; e seu êxito se deve, em parte, a este equívoco. Tratava-se de desfazer, de decompor, de dessedimentar estruturas de todos os tipos, linguísticas, logocêntricas, fonocêntricas, pois o estruturalismo estava dominado pelos modelos linguísticos da chamada linguística estrutural, sócio institucional, política, cultural e filosófica.

Para Ileana Diéguez ${ }^{3}$ (2009), a desmontagem foi uma proposta de investigação interessada em tornar visível o tecido criativo por meio de testemunhos, desconstruções e reconstruções dos próprios criadores. Esse termo, desmontagem, surge na segunda metade do séc. XX, num processo de investigação dos teatros latino-americanos independentes, na busca de um caminho alternativo de outras linguagens cênicas e dramatúrgicas, como outras teorias e pontos de vista.

Com esse procedimento desenvolve-se, então, outras práticas de compartilhamento nas artes cênicas. Uma delas é a exposição pública de certos momentos privados do ato criativo. Evidencia-se o real. Quase nada escapa; até o que não era previsto e que surge espontaneamente no momento. Percebe-se, também, uma maior horizontalidade na relação artista e espectador. A não representação e, sim, apresentação, transcendendo a dimensão contemplativa, propondo modos mais participativos e podendo estar fora dos espaços convencionais e/ou tradicionais de se fazer e fruir arte.

A desmontagem de determinados processos criativos de atores implicou em revelar algumas relações entre investigação e criação. Esses princípios que são desvelados/revelados não são repetidos ou conhecidos, são um emaranhado de experiências à margem do que é comumente considerado como modelo de sucesso. (DIÉGUEZ, 2009, p. 10, tradução nossa).

A pesquisadora se atentou, portanto, para esse processo devido ao abismo em que vários autores/artistas se lançaram, trazendo, para a desmontagem, testemunhos, reflexões, perguntas, experiências e nenhuma certeza, nenhum método e nenhum saber a priori. No entanto, um aspecto comum que aproximava essas desmontagens eram as experiências com o fazer cênico.

\footnotetext{
${ }^{3}$ Ileana Diéguez é uma referência ao tratarmos do conceito de desmontagem na cena contemporânea. Professora da Universidade Autónoma de Mexico, atua em grupo de pesquisa e outras instâncias que abordam o tema em questão.
} 
A desmontagem está longe de prestar-se a algum método, mas consiste em expor diversas experiências e modos como elas acontecem. Não existe um método para as desmontagens, não é possível fixá-la em algum esquema que enrijeça o corpo vivo que é a cena. Cada criador elege as estratégias para tentar acessar ou regressar a esse encontro reflexivo e artístico com o seu próprio material.

Segundo Diéguez, mais que destruir, era preciso compreender o que se havia construído, para então reconstruir. A desmontagem organiza o processo criativo.

\section{O início}

Quando foi estabelecida a tarefa de apresentar uma desmontagem de um percurso/processo criativo dentro da disciplina, fiquei num impasse, pois até então não havia encenado algo, já que venho de uma área esportiva; no entanto, o esporte também me proporcionou alguma sensibilidade artística oriunda do meu percurso na ginástica e na dança. Propuseram-me, então, fazer uma desmontagem da minha vida, mostrando o viés artístico o qual me norteou e me fez chegar ao doutorado em artes cênicas. Então, aceitei a proposta, já que não existe um procedimento engessado na desmontagem e o artista escolhe o que quer expor. A desmontagem sempre é um momento político, é uma estratégia, um momento crítico, de análise, portanto, um processo rico e híbrido, de rever, de memória. Esse processo acabou sendo uma investigação interessante, onde me percebia mergulhando profundamente em algumas questões pessoais. E é essa experiência que eu trago para compartilhar neste artigo. Parti das minhas memórias pessoais, busquei registros visuais (fotos) e de escrita (na forma de diários), relembrei músicas que marcaram certos períodos, revisitei fases performáticas diferentes, reuni material profissional (cursos e projetos) e compus uma apresentação para o meu trabalho até chegar ao meu projeto de pesquisa do doutorado. Essas ações fizeram com que eu organizasse totalmente minha sala de trabalho e meu escritório particular, ou seja, essa preparação foi um processo de reestruturação tanto interna quanto externa.

\section{Minha desmontagem}

Filha de um casal de artistas germânicos vindos ao Brasil após a $2^{\text {a }}$ Guerra Mundial, tive uma educação pautada na preparação para sobrevivência em guerras. Em casa, para que eu fosse reconhecida, tinha que ser a melhor, politicamente correta e verdadeira. Não podia fraquejar, tinha que ser forte e perfeita. Eu não podia ter medo, nem errar e nem chorar. Tinha sempre que andar 
com a cabeça erguida e com o peito projetado para frente. Fui uma criança muito rebelde. Eu queria fazer de tudo. Tinha ânsia para conhecer o mundo... Quando quis fazer música, minha mãe me podou, alegando que eu era muito desafinada. Quando quis fazer balé, meu pai me aconselhou a fazer esgrima, judô, enfim... artes marciais.

Então resolvi percorrer outros caminhos: fui ser baliza em desfiles de sete de setembro. Entrei na ginástica artística e, por ela, conquistei um lugar na seleção mineira. Concomitantemente, comecei a treinar ginástica rítmica, pela qual, mais tarde, estive na Seleção Brasileira durante cinco anos, competindo internacionalmente na Espanha, na Suíça, no Canadá, na Inglaterra e na Alemanha. Vale ressaltar que a dança sempre esteve presente em minha vida, mesmo que indiretamente, pois fazia parte da preparação das ginastas. Por gostar de atividade física, eu sempre buscava novos desafios no esporte. Posso dizer que tive três fases nele: aquela em que eu competia contra os outros, aquela em que eu competia comigo mesma e a atual, em que pratico por prazer.

\section{Entre fugas e encontros}

Acabei me refugiando na ginástica ao vivenciar a separação de meus pais na minha adolescência. Com todos os prós e contras, essa experiência me preparou para a vida.

$\mathrm{Na}$ ginástica, sempre almejei alcançar um movimento tecnicamente perfeito. A música é que trazia um tom poético àquela plasticidade nua e crua. A coreografia era um entrelaçado de movimentos que desafiavam as leis da física e da mecânica. Cada fio desse tecido era um movimento simples que se ligava a outro, tornando-se cada vez mais complexo. Quanto mais desafiadora fosse essa tecelagem, maior era a sua avaliação. Não importava que danos causassem; físicos e/ou emocionais. O que importava era que tínhamos que dar conta de tudo. Essa experiência fez com que eu me remetesse à música Esquinas, de Djavan:

\footnotetext{
Só eu sei, as esquinas por que passei

Só eu sei, só eu sei

Sabe lá, o que é não ter e ter que ter pra dar ${ }^{4}$

Sabe lá, sabe lá... (Djavan, 1984).
}

Se por um lado a performance das ginásticas não se preocupava com um lado poético, por outro, ela também não trazia questões políticas. Não havia questionamentos, nem reflexões, nem críticas. Existia apenas o movimento pelo movimento. Como já relatei, era a música que preenchia e envolvia esse movimento, trazendo-lhe toda potencialidade expressiva. Na Ginástica Rítmica, agregada à música e à coreografia, tínhamos os aparelhos manuais. Os oficiais: corda, bola, arco,

\footnotetext{
${ }^{4}$ Grifo meu, para evidenciar a sensação que eu tinha na época.
} 
fita e maças. Os alternativos: normalmente criados pelos próprios praticantes; porém precisavam ser vistosos e funcionais, pois eram utilizados nos espetáculos de abertura de jogos e outras festividades. Mas, voltando aos aparelhos oficiais, mais uma vez a técnica era soberana em $60 \%$ desses aparelhos (corda, arco e maças). Apenas $40 \%$ deles (bola e fita) permitia transparecer uma fluidez que deixava rastros de uma obra artística no ar, ou seja, onde conseguíamos perceber a plasticidade de uma arte em movimento. Enfim, essa área performativa que é a ginástica rítmica, está sempre em busca pela tríade perfeita: o corpo num treinamento desenfreado e cada vez mais intenso de suas valências físicas e habilidades perceptivas; o aparelho, com a sua técnica de manejo cada vez mais elaborada e desafiando cada vez mais a lei da gravidade; e a música, que, apesar de permitir uma livre escolha, possui restrições que são regidas por regras estabelecidas pelo órgão máximo dessa modalidade esportiva, a Federação Internacional de Ginástica (FIG).

Como eu mesma vivenciei um "treinamento de alto nível”, chegando a participar da Seleção Brasileira de Ginástica Rítmica, e ao sentindo as consequências dos treinos na própria pele, nunca me motivei a desenvolver um trabalho de treinamento, por três motivos:

1. Por mais que se programe um trabalho compensatório ao treinamento, ele nunca conseguirá evitar lesões crônicas;

2. Quando desenvolvemos um trabalho com crianças, que normalmente são movidas por desafios, por mais que as alertemos das possíveis consequências, elas ainda não possuem maturidade suficiente para a compreensão dos possíveis efeitos advindos de treinamentos intensivos;

3. E, mesmo que alertemos os pais, eles se tornam cegos à volúpia de seus egos e vaidades, deixando a ansiedade e a expectativa tomarem conta ao desejarem um lugar no pódio para sua cria, não percebendo a transferência que se faz ao responsabilizar um filho pelo próprio fracasso.

Daí, mais uma vez, passo a vivenciar outras possibilidades.

\section{(D) eficiências}

Ao voltar do meu mestrado em Ciências do Esporte na Alemanha, fui procurada por um grupo de pessoas com as mais diversas deficiências (física, auditiva, visual e mental leve), que me seduziram a desenvolver um trabalho com eles na Dança e na Ginástica Rítmica em Cadeiras de Rodas. 
De início fiquei temerosa, pois não sabia nem mesmo como me comportar frente a eles, que dirá criar algo com eles. Mas estava numa situação onde eu não podia negar, ao ver aqueles olhos brilhando pedindo por atenção e inclusão. Então resolvi enfrentar e comecei a pensar nas várias possibilidades. No entanto, minha mente ainda funcionava na "alta performance", e nem me havia dado conta disso. Pensei, sonhei, planejei, preparei. Conclusão: o primeiro encontro foi uma catástrofe. Terminei o primeiro treino super frustrada, pensando que ninguém voltaria mais. Mas para a minha surpresa, todos estavam lá no treino seguinte. Fiquei muito feliz! Conseguimos num período de seis anos trocar experiências e aprender muito. Participamos de vários eventos científicos da área, apresentando coreografias e relatos de experiência. Na época, foi considerado um trabalho inédito no Brasil.

Concomitantemente a essa época, desenvolvi um projeto numa Clínica de Internação para Pacientes Psiquiátricos. Era interessante perceber como é tênue a linha que separa o que se denomina de doença e o que se denomina de saúde, para tanto, cito uma passagem:

Transtornos mentais são patologias com manifestações psicológicas ou comportamentais associadas a comprometimento do desempenho devido a perturbações biológicas, sociais, psicológicas, genéticas, físicas ou químicas. Cada patologia apresenta sinais e sintomas característicos. (KAPLAN; SADOCK, 1992, p. 1).

Com essas experiências junto a pessoas portadoras de necessidades e cuidados especiais, pude fazer uma reflexão mais apurada sobre a nossa condição humana. Percebi que a qualquer momento um de nós pode estar numa cadeira de rodas ou ter um surto psicótico. Mas também aprendi que para tudo existe um limite. Não é porque uma pessoa possui uma deficiência que devemos tratá-la como "incapaz”, pois todos nós temos as nossas limitações.

Segundo a Convenção n ${ }^{\circ}$ 159/83 da OIT e a Convenção da Guatemala, que foi promulgada

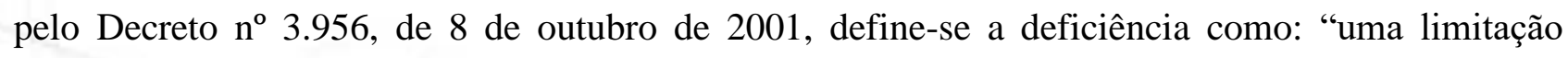
física, mental, sensorial ou múltipla, que incapacite a pessoa para o exercício de atividades normais da vida e que, em razão dessa incapacitação, a pessoa tenha dificuldades de inserção social." (Convenção nº 159/83 da OIT e a Convenção da Guatemala nº 3.956 de 2001).

Descobri que, por mais limitada que uma pessoa seja, ela possui um potencial a ser descoberto e desenvolvido. É preciso acreditar, ter coragem, paciência e muita dedicação. E ter consciência disso pode possibilitar à pessoa recuperar a sua dignidade.

Interessante perceber que, ao longo desse processo, eu transitei de um corpo antes rígido e perfeito para reflexões em torno de corpos fora desse padrão. Dessa forma, fui tomada de certa 
angústia ao perceber mudanças de paradigmas no que diz respeito à questão dos corpos estereotipados.

Continuei buscando algo que pudesse preencher minha inquietude.

\title{
O encontro com a espiritualidade no Yoga
}

Transitando por todos esses caminhos: na busca de um corpo potencialmente perfeito no esporte, vivenciando as limitações desse corpo e percebendo a linha tênue entre saúde e doença, senti necessidade de algo que explicasse melhor a nossa existência. Surge, após vários anos de busca, um encontro mais significativo com a espiritualidade.

\begin{abstract}
Espiritualidade é reconhecida como um fator que contribui para a saúde de muitas pessoas. $\mathrm{O}$ conceito de espiritualidade é encontrado em todas as culturas e sociedades. Ela é expressa nas buscas individuais para um sentido último através da participação na religião e ou crença em Deus, família, naturalismo, racionalismo, humanismo, e nas artes. Todos estes fatores podem influenciar na maneira como os pacientes e os cuidadores profissionais da saúde percebem a saúde e a doença e como eles interagem uns com os outros, (PUCHALSKI, 2001, p.352-7).
\end{abstract}

Portanto, cada cultura e cada sociedade entende a espiritualidade segundo os seus condicionamentos e as suas crenças. É necessário que algo faça sentido para que possamos acreditar. E na busca desse sentido, aos 40 anos, tive acesso ao Yoga, que não é considerado uma religião e sim uma filosofia de vida, e que me proporciona um encontro comigo mesma. Identifiquei-me com os seus ensinamentos. Seu significado maior: união. Foi o meu despertar para a espiritualidade. Passei pelas experiências da Hatha ${ }^{5}$ e da Raja Yoga ${ }^{6}$.

Ao adentrar no mundo do Yoga pude perceber a espiritualidade mais claramente. O Yoga contribui para a nossa saúde, pois, além de nos fornecer uma atividade física pautada no alongamento, na força e no equilíbrio, também nos oportuniza o relaxamento e momentos de meditação. Ao estudar o Yoga, passei a refletir mais sobre vários aspectos da vida, de comportamentos, de ensinamentos, de crescimentos, de desenvolvimentos, de valores e princípios.

Aprendi a observar meu corpo, minhas sensações, meu estado físico, mental e emocional. Com isso aprendi a respeitar os meus limites, ao contrário do que eu fazia na minha fase de atleta, em que eu sempre estava rompendo com os meus limites, o que consequentemente deixou marcas

\footnotetext{
${ }^{5}$ Hatha-yoga é o campo do Yoga que abrange as posturas psicofísicas, contendo as ásanas (exercícios físicos), pranayamas (técnicas respiratórias) e dhyana (relaxamento).

${ }^{6}$ Raja-yoga é o campo do Yoga que estuda técnicas de meditação.
} 
que se tornaram crônicas. Porém, ao me envolver com o Yoga, pude perceber o quanto o meu corpo/mente/emoção são maleáveis. Existe uma expansão e um recolhimento natural e, se respeitados, conseguimos ter uma vida mais equilibrada, mais suave, mais fluída; ou seja, mais saudável.

O Yoga é uma visão peculiar sobre o ser humano e seu papel na ordem das coisas, bem como um caminho de autoanálise que pode ser colocado em prática, prescindindo de qualquer teoria ou crença. Um caminho que conduz o homem a compreender verdadeiramente a si mesmo [...] Yoga também é liberdade. Libertar-se de condicionamentos e preconceitos, por exemplo. Está escrito na Bhagavadgìtā (escritura sagrada Hindú) [...] Perfeição no Yoga é fazer as ações em harmonia com o bem comum e com o reconhecimento de que nosso privilégio é agir, e não tentar controlar ou escolher os resultados das ações. Noutras palavras, perfeição significa viver consciente [...] é permanecer totalmente consciente o tempo todo, de cada ato, a cada momento [...] (KUPFER, 2000).

Na Raja Yoga, passei por experiências com algumas técnicas meditativas. Aprendi a acalmar a mente, a relaxar o corpo e buscar um estado de atenção plena; alcançando assim um estado mental alterado. Esse estado é a principal proposição da meditação.

Parafraseando Yogananda (2001), podemos verificar a relação matemática que existe entre a frequência respiratória do homem e seus vários estados de consciência. Ao silenciar a mente, conseguimos também uma respiração lenta, a qual proporciona um estado salutar no indivíduo. Já uma respiração rápida ou irregular acompanha estados emotivos prejudiciais.

Aspecto curioso é que durante toda a minha vida tive interesse por terapias complementares/alternativas/holísticas, talvez por perceber a limitação da medicina alopática ${ }^{7}$, como também por essas terapias abordarem outros aspectos, principalmente no campo vibracional, o qual a medicina comum não consegue acessar.

Todas as terapias podem ser consideradas complementares e/ou alternativas. Tanto a terapia tradicional quanto as demais podem prescindir de outras terapias atuando individualmente. Quando todas elas, ao necessitarem do auxílio de outras, são consideradas terapias complementares. (GIMENEZ; REINERS, 2007).

Desse modo, prefiro adotar o termo mais antigo, o holístico, pela visão mais completa sobre saúde e doença, já que a terapia complementar pode ser vista como a associação de duas terapias alopáticas e a terapia alternativa possuir um caráter de pouca credibilidade.

No enfoque holístico a doença do corpo físico é apenas, e tão somente, o reflexo ou a somatização das desarmonias já existentes nos corpos energéticos e ou emocionais. Assim sendo o tratamento holístico visa tratar não apenas as dores ou desajustes do corpo físico, ou seja, não somente o efeito, mas sim, busca detectar a origem do mal e tratá-lo para que assim deixe de existir não só o mal, mas também a causa que o provoca. (CARDIM).

7 Medicina alopática refere-se à medicina tradicional, que não necessariamente está vinculada às terapias alternativas/complementares/holísticas, como a acupuntura, a homeopatia, a fitoterapia, dentre outras. 
O Yoga faz parte das várias outras terapias holísticas que vivenciei, algumas como paciente e outras como facilitadora, e que, hoje, compartilham com o que eu realmente acredito. Citando algumas delas: Antroposofia, Saúde Quântica, Liang Gong, Constelação Familiar, Shiatzu, Acupuntura, Microfisioterapia, Magnified Healing, Danças Circulares, dentre outras.

\section{Nova etapa de vida}

Após todas essas experiências pessoais e profissionais, passo por uma situação de vida e morte. Essa sim foi o marco para uma nova etapa na minha existência. Meu período de recuperação foi marcado pela música Paciência, de Lenine, na qual retirava forças para vencer essa fase difícil.

\footnotetext{
Mesmo quando tudo pede um pouco mais de calma

Até quando o corpo pede um pouco mais de alma

A vida não para

Enquanto o tempo acelera e pede pressa

Eu me recuso faço hora vou na valsa

A vida é tão rara

Enquanto todo mundo espera a cura do mal

E a loucura finge que isso tudo é normal

Eu finjo ter paciência

E o mundo vai girando cada vez mais veloz

A gente espera do mundo e o mundo espera de nós

Um pouco mais de paciência
}

Será que é tempo que lhe falta pra perceber

Será que temos esse tempo pra perder

E quem quer saber

A vida é tão rara (Tão rara)... (Lenine, 2006).

Deparava-me com a letra com a qual entrava num processo de reflexão. Este período póscirúrgico foi para mim um momento de luta individual para sobreviver e em que tudo dependia única e exclusivamente de mim. Tive que recorrer à alma para tentar ter calma, o que foi extremamente complicado. Percebi o quanto é difícil respeitar o tempo necessário de cada um ou de cada processo. É preciso passar pela vida com consciência. E, com certeza, em algum momento e de alguma forma ela irá surgir. Das minhas reflexões, o que se evidenciou foi a convicção de que precisamos eliminar a pressa, pois ela só nos cega, emudece e ensurdece... fazendo-nos adoecer. Com a doença que se instala com o avançar da idade é que nos damos conta de que: ah..., se eu tivesse me permitido mais..., se eu tivesse vivido mais as coisas belas da vida!!! Chegar nesse ponto dói muito, porque é impossível voltar para fazer diferente. Temos que, agora, fazer diferente a partir desta tomada de consciência tão dura! Não podemos tão pouco ficar na inércia. Pude perceber também que, quando eu necessitava me centrar, não conseguia achar o meu eixo, pois eu sempre 
estive numa aceleração que não permitia enraizar, ter suporte, me firmar, já que o meu equilíbrio era sempre dinâmico, como um malabarista. Esse equilíbrio dinâmico traz a experiência da primeira lei de Newton (Lei da Inércia), lei esta que se refere a: quando um corpo em movimento é parado bruscamente, os elementos que estão dentro deste corpo tendem a continuar o movimento. Então, se de repente pararmos no meio desta correria mundana, certamente, de alguma forma, iremos nos ferir. E a gente entra nessa roda "viva" da vida, onde não nos entendemos mais e nem entendemos mais o outro, porque não temos tempo para escutar o outro, pois achamos que, se pararmos para escutar o outro, perderemos tempo. No mundo atual não podemos nos dar o luxo de perder tempo; assim como diz um ditado popular: "tempo é dinheiro". Como se o dinheiro fosse tudo.... A escuta é importante para que possamos compreender o outro e até compreender a nós mesmos. Precisamos sim, estar atentos em tempo integral aos nossos pensamentos, atitudes, falas e comportamentos.

\section{MoVidAção (movimento+vida+ação)}

Mergulhada nas reflexões que a vida me presenteou e na busca por experiências que fazem sentido para os meus alunos, comecei a desenvolver uma metodologia, na qual coloco em prática as vivências que tive no campo das terapias holísticas, acionando memórias celulares ${ }^{8}$ e valorizando o movimento próprio de cada indivíduo.

Pautada em Bondía (2002), quando ele discursa sobre o desejo de realidade que temos, e que se relaciona com a vontade de viver, comecei a refletir sobre o aspecto pedagógico de minhas ações. Isso porque vivemos uma vida desvitalizada, buscando a vida na vida. Sentimos falta de algo que não encontramos na realidade que nos é colocada. "Do mesmo modo que reivindicamos que a vida esteja viva, reivindicamos também que a realidade seja real, ou seja, que tenha a validade, a força, a presença, a intensidade e o brilho do real.” (BONDÍA, 2008, p.186). O real só acontece quando estamos abertos às novas experiências. Abertos ao ponto de provocar estranheza, exterioridade e alteridade.

Por meio da investigação educativa, que é formada por práticas e discursos que propõem conhecimentos e transformações, podemos aguçar o desejo de realidade, ou seja, ver com outro olhar, dizer de outro modo e pensar de outra forma. É como nós interagimos com o mundo, com os outros e com nós mesmos.

\footnotetext{
${ }^{8}$ Refiro-me às memórias celulares, neste caso, aos registros inconscientes que trazemos em nosso corpo de experiências dos nossos antepassados e de nós mesmos, que acabam interferindo no que somos e/ou sofremos hoje.
} 
O real não é objeto, é deixar-se afetar; não é representação, mas presença; nem tão pouco é intencional, é uma aproximação amorosa; não é também lógico, pois foge do discurso de que nada existe sem razão; o real escapa das explicações. O desejo de realidade é um desejo pela surpresa.

A aproximação amorosa tem relação direta com a atenção. É o estar presente, o cuidar, o escutar e o esperar na relação consigo, com o outro e com o mundo. Para que isso aconteça precisamos ter confiança, amor e paciência.

E é justamente tudo isso que desejo provocar nos meus alunos com essa pesquisa de doutorado intitulada: Entre memórias e criações: o (in) visível de um corpo dançante.

Preocupo-me quando vejo como se têm trabalhado os processos coreográficos na educação. O que eu percebo são mutilações de seres potencialmente criativos em detrimento ao que já está pronto. Perguntamos: Isto é educação? Que valores estamos passando para as próximas gerações? Que potenciais estamos desenvolvendo? Onde ficam os processos de criação, amadurecimento, reflexões e desenvolvimento? Queremos lapidar todas as pedras de uma mesma maneira? Onde está a valorização do potencial interno e individual da diversidade?

Diante disso, venho propor outra possibilidade metodológica de um processo coreográfico, na qual o produto possa conter a história e as vivências de cada integrante, além de explorar o seu potencial de criação. E, ainda, favorecer a experiência da meditação, para possibilitar a ampliação das percepções e, consequentemente, acessos em níveis mais profundos da consciência.

Como suporte desse processo de criação, parafraseio Favaretto (2010), quando reporta que a arte tem seu papel importante na formação do indivíduo, já que ela instiga o descobrir do potencial criativo de cada ser. E sabemos que todas as grandes invenções da humanidade foram advindas da criatividade. Podemos até dizer que a arte nos faz aproximar de um estado espiritual, ao não valorizar a matéria (capitalismo) e, sim, a conexão com a natureza. E ainda, a arte pode ser um processo terapêutico, quando falamos de insights e catarses. Um processo muitas vezes solitário, porém de autodescobertas. É uma forma de comunicação tanto intrínseca quanto extrínseca, verbal e não verbal, literal e abstrata, provocadora e contemplativa.

Enfim, é uma área de uma infinidade de possibilidades para um desenvolvimento integral de cada um de nós, de forma a possibilitar acessos às memórias próprias e/ou de antepassados, onde existe a possibilidade de um entrelaçamento de histórias de vida.

Ainda pautada em Favaretto (2010, p.225): “Consideramos que o essencial é o acesso à experiência estética a partir do contato com a atitude e o trabalho dos artistas, portanto, como pensar e propor as mediações estratégicas para compatibilizar os dois termos da equação: educação e 
arte?", venho propor uma possibilidade de vivenciar arte e educação, a partir do momento em que permitimos o despertar da criação e que ao mesmo tempo possa fazer sentido para quem a cria e vivencia.

\section{Reflexão final}

Diante das observações e socializações dos alunos e professores da disciplina Pedagogia(s) do Teatro: Práticas Contemporâneas, do programa DINTER UFU/UNIRIO-2013, que participaram deste trabalho de desmontagem, e pautada em Bondía (2008), o qual relata que a aprendizagem acontece quando o indivíduo vivencia uma experiência que lhe faz sentido e que discorre sobre a aproximação amorosa como meio de se buscar o desejo da realidade, pude perceber a força do grupo, ao respeitar cada indivíduo com as suas histórias, as suas marcas, as suas fragilidades e as suas potências. Cada um trouxe, em sua desmontagem, questões pessoais, políticas, sociais, existenciais, afetivas, técnicas, educacionais, dramatúrgicas, performativas, espaciais, enfim, vimos uma gama de possibilidades que se entrelaçavam tanto individualmente quanto com o grupo, e que teciam ao final de cada apresentação um rico tecido quântico ${ }^{9}$. Tudo isso só foi possível pela segurança, tranquilidade e afeto que o grupo fornecia para cada integrante. Portanto, segundo Bondía (2008): "Somente a confiança, a paciência e a amorosidade podem nos colocar em uma relação em que o mundo, os outros e nós mesmos tenhamos a validade, o brilho, a força e a intensidade do real".

Sem sombra de dúvidas, esse processo de desconstrução/desmontagem só foi possível pela característica da turma e da professora Dra. Mara Lúcia Leal, de modo que todos se acolhiam, pois se percebia ser um processo híbrido e profundo, em que passagens difíceis iam se desvelando. Eu mesma entrei em processos intensos, de insights e de dor, porém a cada lágrima escorrida pela face desfazia-se uma ferida.

Então pergunto: desconstrução, desmontagem ou reconstrução, ou tudo isso ao mesmo tempo? Deixo a vocês desvelarem esse enigma!

\section{Referências}

BONDÍA, Jorge Larrosa. Notas sobre a experiência e o saber de experiência. Revista Brasileira de Educação. Tradução de João Wanderley Geraldi, n. 19, jan/fev/mar/abr de 2002.

\footnotetext{
${ }^{9}$ Tecido quântico relaciona-se com as teorias da física quântica, onde tudo está interconectado, inter-relacionado e interdependente.
} 
BONDÍA, Jorge Larrosa. Desejo de realidade. Experiência e alteridade na investigação educativa. In: BORBA, Siomara; KOHAN, Walter (org.). Filosofia, aprendizagem, experiência. Belo Horizonte: Autêntica, 2008. p. 185 - 194.

CARDIM, Ronaldo. Terapia Holística. Disponível em: <http://somostodosum.ig.com.br/conteudo/conteudo.asp?id=01224>. Acesso em: 01 ago. 2013.

CONVENÇÃO n ${ }^{\circ}$ 159/83 da OIT e a Convenção da Guatemala, que foi promulgada pelo Decreto $\mathrm{n}^{\mathrm{o}} 3.956$, de 8 de outubro de 2001.

DERRIDÁ, Jacques. Carta a un amigo japonés. El tiempo de una tesis. Deconstrucción e implicaciones conceptuales. Barcelona: Proyecto A., 1997.

DIÉGUEZ, Ileana (comp.). Des/Tejiendo Escenas. Desmontajes: procesos de investigación y creación. Cidade do México: Universidad Iberoamericana, 2009.

DIÉGUEZ, Ileana. De malestares teatrales y vacíos representacionales: el teatro trascendido. In: CORNAGO, Óscar (coord.). Utopías de la proximidad en el contexto de la globalización. La creación escénica en Iberoamérica. Cuenca: Universidad de Castilla-la Mancha, 2010.

FAVARETTO, Celso F. Arte Contemporânea e Educação. Revista Iberoamericana de Educación, v. 53, p. 225-235, 2010. Disponível em: 〈http://www.rieoei.org/rie53a10.pdf >. Acesso em: 01 ago. 2013.

GIMENEZ, C. S.; REINERS, A. A. O. Terapias alternativas: um estudo bibliográfico / Alternative therapies: a bibliographical study; Nursing (São Paulo);10(110):324-328, jul. 2007. ilus, tab, graf. Disponível em: <http://decs.bvs.br/cgi-bin/wxis1660.exe/decsserver/?IsisScript=../cgibin/decsserver/decsserver.xis\&previous_page=homepage\&task=exact_term\&interface_language=p \&search_language=p\&search_exp=Terapias\%20Complementares $>$. Acesso em: 01 ago. 2013.

GONSALVES, Elisa. Iniciação à pesquisa científica. 3ed. Campinas-SP: Alínea, 2003.

GOSWAMI, Amit. A Janela Visionária. São Paulo: Cultrix, 2000.

JUNG, Carl. Os arquétipos e o inconsciente coletivo. Rio de Janeiro: Vozes, 1976.

KAPLAN, Harold I.; SADOCK, Benjamin J. Manual de Psiquiatria Clínica. Rio de Janeiro: MEDSI, 1992.

KUPFER, Pedro. $\quad$ O que é Yoga?, 2000. Disponível em: <http://www.yoga.pro.br/artigos/350/3047/o-que-e-o-yoga>. Acesso em: 01 ago. 2013.

LABAN, Rudolf. (Org. Lisa Ullmann) Domínio do movimento. Tradução de Anna Maria Barros De Vecci e Maria Silvia Mourão Netto. São Paulo: Summus, 1978.

LABAN, Rudolf. Der moderne Ausdruckstanz in der Erziehung. 2 ed., Wilhelmshaven: Heinrichshofen, 1984. 
Die Kunst der Bewegung. Wilhelmshaven: Noetzel, Heinrichshofen-Bücher, 1988.

PUCHALSKI, CM. The hole of spirituality in health care. BUMC Proceedings 2001, 14:352357. Disponível em: $<$ http://www.unifesp.br/centros/cehfi/portal/index.php?option=com_content\&view=article \&id=37:p or-que-pesquisar-a-espiritualidade-na-saude $\&$ catid=16:sobre-espiritualidade-e-saude $\&$ Itemid=3 $>$. Acesso em: 01 ago. 2013.

STEINER, Rudolf. O conhecimento dos mundos superiores - A iniciação. 7 ed., São Paulo: Antroposófica Ltda, 2007.

YOGANANDA, Paramahansa. A ciência do Yoga. 2001. Disponível em: <http://www.yoga.pro.br/artigos/205/34/a-ciencia-do-kriya-yoga>. Acesso em: 01 ago. 2013.

\section{Referências sonoras:}

Músicas: Paciência de Lenine / Esquinas de Djavan.

Link: 〈http://www.vagalume.com.br/lenine/paciencia.html\#ixzz2biGqFrK3>. Acesso em: 01 ago. 2013.

Link: 〈http://www.vagalume.com.br/djavan/esquinas.html\#ixzz2biINpjXf〉. Acesso em 01 ago. 2013. 